\title{
Correction to: Genetically engineered probiotic Saccharomyces cerevisiae strains mature human dendritic cells and stimulate gag-specific memory $\mathrm{CD}^{+} \mathrm{T}$ cells ex vivo
}

\author{
Mariana L. Palma ${ }^{1} \cdot$ Tatiana M. Garcia-Bates $^{1} \cdot$ Flaviano S. Martins $^{2} \cdot$ Bruno Douradinha $^{3}$ (D) \\ Published online: 20 May 2019 \\ (C) Springer-Verlag GmbH Germany, part of Springer Nature 2019
}

\section{Correction to: Applied Microbiology and Biotechnology} https://doi.org/10.1007/s00253-019-09842-8

The published online version contains a mistake.

In the Funding section, the following statement is missing: The MACS cohort study was supported by the NIH, National Institute of Allergy and Infectious Diseases grant U01-AI35041.

Publisher's note Springer Nature remains neutral with regard to jurisdictional claims in published maps and institutional affiliations.

The online version of the original article can be found at https://doi.org/ 10.1007/s00253-019-09842-8

Bruno Douradinha

bdouradinha@fondazionerimed.com

1 Department of Infectious Diseases and Microbiology, University of Pittsburgh Graduate School of Public Health, Pittsburgh, PA 15261, USA

2 Departamento de Microbiologia, Instituto de Ciências Biológicas, Universidade Federal de Minas Gerais, Belo Horizonte, MG 31270-901, Brazil

3 Unità di Medicina Rigenerativa ed Immunologia, Fondazione Ri.MED c/o IRCCS-ISM, Via Ernesto Tricomi 5, 90127, Palermo, Italy 